\title{
Psychometric properties of the persian version of the inventory of statements about self-injury (ISAS)
}

\author{
Omid Rezaei ${ }^{1}$, Mojtaba Elhami Athar ${ }^{2}$, Ali Ebrahimi ${ }^{3 *}$, Elham Azamian Jazi ${ }^{2}$, Sirwan Karimi ${ }^{2}$, Shima Ataie ${ }^{4}$, \\ Ehsan Taheri ${ }^{5}$, Mahboubeh Abbassian ${ }^{5}$ and Eric A Storch ${ }^{6}$
}

\begin{abstract}
Background: Non-suicidal self-injury (NSSI) is a serious public health problem prevalent among adolescents and young adults. The present study examines the factor structure, internal consistency, and validity of the Persian version of the Inventory of Statements About Self-injury (ISAS), a self-report measure designed to comprehensively assess non-suicidal self-injury (NSSI).

Methods: A total of 655 Iranian school-attending adolescents completed study measures online, and 246 youth (37.70\%) (M age $=15.38, S D \pm 0.50 ; 53 \%$ female) reported a history of NSSI at least once during their lifetime.

Results: Confirmatory factor analysis supported the proposed two-factor model of ISAS (i.e., Interpersonal and Intrapersonal dimensions), which were internally consistent and yielded direct associations with converging correlates (e.g., depression, anxiety, irritability, and anger).
\end{abstract}

Conclusions: Findings indicated that the Persian version of the ISAS has sound psychometric properties and is a valid and reliable self-report measure of NSSI.

Keywords: Non-suicidal self-injury, Deliberate self-harm, Psychometric properties, Assessment, Persian version

\section{Background}

Non-suicidal self-injury (NSSI) refers to any deliberate and direct destruction of body tissue in the absence of suicidal intention $[1,2]$. NSSI manifests in various behavioral patterns such as cutting or carving the skin, burning the skin, or deliberately fracturing one's bones [3] and is associated with psychiatric casenesses such as Borderline Personality Disorder (BPD), suicidality, anxiety, and depression e.g., [4-7]. The prevalence of NSSI is common with symptoms endorsed in approximately 20-30\% of adolescents in Turkey [8], Pakistan [9], Korea [3], Belgium [10], the USA [11], Germany [12],

\footnotetext{
* Correspondence: alipsychologist69@gmail.com

${ }^{3}$ Candidate in Clinical Psychology, the University of Social Welfare and Rehabilitation Sciences, 1985713871 Tehran, Iran

Full list of author information is available at the end of the article
}

and Spain [13]. Concerning the prevalence of NSSI in Iran, a lifetime prevalence of $12.3 \%$ without gender differences was reported among Iranian university students [14]; however, to our knowledge, no study has yet examined the prevalence of NSSI among Iranian schoolattending adolescents.

NSSI often presents during adolescence and is a significant mental health challenge affecting about $70 \%$ of children and adolescents with mental health problems e.g., [15-20]. Across six geographical regions (Asia, Australia/New Zealand, Canada, Europe, United Kingdom, USA) over 19 years, Swannell et al. (2014) reported that the prevalence of NSSI was $17.2 \%$ for adolescents across different countries, schools, universities, and in community-based samples. Given the high prevalence of

(c) The Author(s). 2021 Open Access This article is licensed under a Creative Commons Attribution 4.0 International License, which permits use, sharing, adaptation, distribution and reproduction in any medium or format, as long as you give appropriate credit to the original author(s) and the source, provide a link to the Creative Commons licence, and indicate if changes were made. The images or other third party material in this article are included in the article's Creative Commons licence, unless indicated otherwise in a credit line to the material. If material is not included in the article's Creative Commons licence and your intended use is not permitted by statutory regulation or exceeds the permitted use, you will need to obtain permission directly from the copyright holder. To view a copy of this licence, visit http://creativecommons.org/licenses/by/4.0/ The Creative Commons Public Domain Dedication waiver (http://creativecommons.org/publicdomain/zero/1.0/) applies to the data made available in this article, unless otherwise stated in a credit line to the data. 
NSSI among adolescents [21, 22], assessing NSSI among this age group is of utmost importance.

The Inventory of Statements about Self-Injury (ISAS), developed by Klonsky et al. [4], assesses different NSSI functions. The ISAS consists of two parts. Part I assesses the frequency of 12 different types of NSSI behaviors, which were performed "intentionally and without suicidal intent," including banging/hitting, biting, burning, carving, cutting, wound picking, needle-sticking, pinching, hair pulling, rubbing skin against rough surfaces, severe scratching, and swallowing chemicals. Additionally, this part includes five further questions evaluating descriptive and contextual factors of NSSI, including the age of onset, the experience of pain during NSSI, whether NSSI is performed alone or around others, the time between the urge to self-injure and the act of NSSI, and if the person wants to end self-injuring or not. If participants confirm one or more NSSI behaviors, they are directed to complete Part II of the ISAS, which evaluates five intrapersonal and eight interpersonal NSSI functions (i.e., Affect Regulation, Anti-dissociation, Antisuicide, Autonomy, Interpersonal boundaries, Interpersonal influence, Marking distress, Peer bonding, Selfcare, Self-punishment, Revenge, Sensation seeking, and Toughness) through 39 items with three items for each function, rated on a 3-point Likert type scale, ranging from 0 (not relevant) to 2 (very relevant). A higher score corresponds to a greater number of functions or motives for engaging in self-injury.

Given the importance of NSSI assessment, the ISAS has been translated and studied in various countries, including Sweden [23], Turkey [24], Australia [25], South Korea [3], Spain [26], Iran [27], Pakistan [9], and Norway [28]. In the original study, Klonsky et al. [4] examined the psychometrics of ISAS with 235 college students in the USA who had performed at least one NSSI behavior. Results of exploratory factor analysis (EFA) with Promax rotation indicated a robust two-factor solution. The first factor represented eight interpersonal functions (Autonomy, Interpersonal boundaries, Interpersonal influence, Peer-bonding, Revenge, Self-care, Sensation-seeking, and Toughness), and the second factor represented five Intrapersonal functions (Affect regulation, Antidissociation, Anti-suicide, Marking distress, and Selfpunishment). The same factor structure was replicated in Turkey [24], Australia [25], South Korea [3], and Pakistan [9]. Similarly, the two-factor model yielded a good fit with the sample of eating disorder or cluster B personality disorder patients in Spain [26]. In the most recent study with a sample of Norwegian students, the results confirmed the two-factor model of ISAS. The "Marking distress" function loaded on the interpersonal factor, which was loaded on the intrapersonal factor in the original study by Klonsky et al. [4]. The "self-care "function was also loaded on the intrapersonal factor, which belonged to the interpersonal factor in the original study [28]. In Iran, Zarghami et al. [27] examined the psychometrics of the ISAS among adult opioid and alcohol abusers. The EFA revealed a single-factor solution, which yielded an adequate fit in the subsequent confirmatory factor analysis (CFA). While important, Zarghami et al. [27] correlated seven error covariances in their one-factor solution, which may not provide a clear interpretation of the true factor structure $[29,30]$.

Beyond a stable factor structure, other psychometric properties of the ISAS are positive. The internal consistency of ISAS' factors and the 13 functions were in the acceptable to excellent range in both community $[3,4,24,25,28,31]$ and clinical samples $[9,23,26,27]$. Additionally, in support of their convergent validity, ISAS scores were associated with related constructs such as borderline personality symptoms, suicidality, depression, anxiety, impulsivity, and contextual variables such as the tendency to selfinjure alone, suicidal ideations, and decreased resilience $[3,4,24,25,27,28,31]$; ISAS scores were also positively correlated with emotion dysregulation [26, 28] and negatively with distress tolerance [27].

While ISAS is a widely used measure to assess NSSI, its psychometrics have not been comprehensively examined in the Iranian youth sample, and thus, it is unclear if the findings from other cultures are generalizable to Iran [32-34]. For instance, in Iran, the predominant religious traditions strongly prohibit suicidal behavior. Moreover, this practice is evident in schools, where adolescents are taught that a suicide attempt is among Islam's gravest sins, and if one attempts suicide, he/she will be deprived of paradise and its merits. Therefore, it is likely that individuals may feel guilty once they attempt suicide, and they may engage in NSSI instead of suicidal attempts, which may result in higher scores on the antisuicide function of NSSI. Thus, a separate study is needed to examine the ISAS in Iranian culture. Furthermore, despite the prevalence of NSSI among Iranian adolescents [35], NSSI is not a well-known and wellstudied subject in Iran. Thus, this gap needs to be filled using valid NSSI measures. To this end, the current study investigated the factor structure, reliability, and validity of the ISAS with a sample of 655 Iranian school attending adolescents. CFAs were conducted to examine the proposed two-factor structure of the ISAS and the one-factor model, which has been proposed by Zarghami et al. [27] with an Iranian sample of adult opioid and alcohol abusers. Then, the reliability of the ISAS scores was estimated using Cronbach's alpha coefficient $(\alpha)$ and mean inter-item correlations (MIC) values. Finally, the convergent validity of the ISAS scores was examined by calculating the associations between ISAS scores and 
related variables, such as depression and anxiety e.g., [24], suicidal ideation/ suicide attempts e.g., [3], and emotion regulation e.g., [26, 28]. We hypothesized that the two-factor model of the NSSI yield adequate model fit and enjoy acceptable internal consistency. We also expected ISAS scores to be correlated positively with external correlates of interest (e.g., depression, anxiety, irritability, and expressive suppression) e.g., [24, 26, 28].

\section{Methods}

\section{Participants}

Participants were 655 school-attending youth aged 13-17 years old who were recruited between November 2020 to April 2021. Of the 655 participants, $246\left(M_{\text {age }}=\right.$ $15.38, S D \pm 0.50$; $53 \%$ female) respondents reported a history of NSSI at least once during their lifetime, and the analysis was computed based on the data from the latter group.

\section{Procedure}

The ethics committee of the Psychosis Research Center, University of Social Welfare and Rehabilitation Sciences approved this study (code number: IR.USWR.REC.1399.223). Data were collected through a secured online platform. Therefore, we shared the online forms of the questionnaires with the social media groups of schools in Tehran, and 655 completed questionnaires were gathered.

\section{Measures \\ ISAS}

The ISAS [4] assesses the frequency and functions of NSSI and consists of two sections. The nature and psychometric properties have been reviewed previously.

Persian ISAS. For the present study, the ISAS was translated to Persian by two translators who were also fluent in English. Subsequently, Persian translations were translated back from Persian to English by a third, independent translator. Next, the back-translated English version of the ISAS was shared with a psychiatrist whose comments were implemented in reviewing and revising the measure.

\section{Emotion regulation questionnaire}

The Emotion Regulation Questionnaire (ERQ; 36) is a 10 -item self-report measure that includes two dimensions corresponding to two different emotion regulation strategies, i.e., cognitive reappraisal (6 items) and expressive suppression (4 items). Items are rated on a 7-pointLikert scale from 1 (strongly disagree) to 7 (strongly agree). The Persian version of the ERQ replicated the original two-factor model with adequate validity and excellent internal consistency for the expressive suppression $(\alpha: 0.85)$ and cognitive reappraisal ( $\alpha: 0.87)$ dimensions [37]. Cronbach's alpha and MICs for EQR dimensions can be retrieved from Table 1.

\section{DSM-5 self-rated level 1 cross-cutting symptom measure-child age 11-17}

DSM-5 Self-Rated Level 1 Cross-Cutting Symptom Measure-Child Age 11-17 [1] contains 25 questions that assess 12 psychiatric domains, including depression, anger, irritability, mania, anxiety, somatic symptoms, inattention, suicidal ideation/attempt, psychosis, sleep disturbance, repetitive thoughts and behaviors, and substance use. Each item asks the child, age 11-17, to rate how much (or how often) he or she has been bothered by the specific symptom during the recent two weeks. Nineteen of the 25 items on the measure are rated on a 5-point scale ranging from 0 (none or not at all) to 4 (severe or nearly every day). The suicidal ideation, suicide attempt, and substance abuse items are rated on a "Yes or No" scale.

\section{Data analysis}

Descriptive statistics of the study variables for the NSSI sample and the total sample are presented in Tables 1 and 2, respectively. We handled missing values using the series mean method in SPSS 20 and used the Boxplot method was to address outliers, resulting in a sample size of 655 . Using data from 247 youth who had performed at least one NSSI behavior, we then performed CFAs (maximum likelihood estimator) using the Lisrel 8.80 software [38] to test the original two-factor [4] and the one-factor [27] models of the ISAS. Model fit indices included the comparative fit index (CFI) and the Tucker-Lewis index (TLI) $\geq 0.90$ as indicating acceptable fit and the root mean square error of approximation $($ RMSEA $) \leq 0.08$ indicating acceptable model fit $[39,40]$.

Next, we examined the internal consistency of the ISAS scores based on Cronbach's alpha $(\alpha)$ and mean inter-item correlation (MIC) values. Alpha coefficient ranges between 0 and 1 , and since it tends to underestimate reliability when there are few items in a subscale, we calculated MIC values too, which are not dependent on the number of items in a scale and should be in the range of 0.15 to 0.50 to be considered adequate [41].

Finally, we evaluated the convergent validity of ISAS scores by examining Pearson correlation coefficients between the ISAS dimensions and correlates of interest (e.g., depression, anger, anxiety, suicidal ideation/ suicide attempts, and emotion regulation strategies).

\section{Results}

Of the whole sample $(n=655), 247(37.70 \%)$ respondents reported a history of NSSI at least once during their lifetime. The most commonly endorsed means of NSSI were interfering with wound healing (69\%), 
Table 1 Descriptive Statistics of ISAS, ERQ, and CCSM Variables $(n=247)$

\begin{tabular}{|c|c|c|c|c|c|}
\hline Measures & Mean $(S D)$ & Skewness & Kurtosis & $a$ & MIC \\
\hline ISAS Interpersonal Functions & $5.24(6.45)$ & 1.45 & 1.62 & 0.89 & 0.54 \\
\hline Interpersonal boundaries & $0.77(1.14)$ & 1.49 & 1.50 & 0.60 & 0.35 \\
\hline Interpersonal influence & $0.67(1.09)$ & 1.77 & 3.16 & 0.52 & 0.27 \\
\hline Toughness & $1.07(1.43)$ & 1.34 & 1.22 & 0.75 & 0.49 \\
\hline Autonomy & $0.87(1.37)$ & 1.64 & 2.02 & 0.79 & 0.56 \\
\hline Sensation seeking & $0.74(1.11)$ & 1.56 & 1.85 & 0.52 & 0.29 \\
\hline Revenge & $0.60(1.08)$ & 2.09 & 4.34 & 0.60 & 0.34 \\
\hline Peer-bonding & $0.49(1)$ & 2.27 & 5.07 & 0.61 & 0.36 \\
\hline ISAS Intrapersonal Functions & $7.54(7.04)$ & 0.87 & 0.10 & 0.87 & 0.54 \\
\hline Affect-regulation & $1.77(1.75)$ & 0.67 & -0.54 & 0.72 & 0.46 \\
\hline Self-punishment & $1.25(1.53)$ & 1.24 & 0.98 & 0.67 & 0.41 \\
\hline Anti-dissociation & $1.07(1.37)$ & 1.04 & 0.41 & 0.62 & 0.35 \\
\hline Anti-suicide & $1.21(1.71)$ & 1.30 & 0.72 & 0.74 & 0.50 \\
\hline Self-care & $1.25(1.37)$ & 1.04 & 0.42 & 0.56 & 0.32 \\
\hline Marking distress & $0.94(1.29)$ & 1.26 & 0.72 & 0.79 & 0.56 \\
\hline \multicolumn{6}{|l|}{ ERQ } \\
\hline Cognitive reappraisal & $29.84(6.08)$ & -0.56 & 1.28 & 0.62 & 0.22 \\
\hline Expressive suppression & $17.23(5.02)$ & -0.11 & -0.39 & 0.57 & 0.25 \\
\hline \multicolumn{6}{|l|}{ CCSM } \\
\hline Somatic symptoms & $1.93(1.95)$ & 1.02 & 0.61 & 0.50 & 0.34 \\
\hline Sleep problems & $1.37(1.57)$ & 0.64 & -1.22 & * & * \\
\hline Inattention & $1.23(1.43)$ & 0.80 & -0.78 & * & * \\
\hline Depression & $3.11(2.65)$ & 0.38 & -1.10 & 0.48 & 0.31 \\
\hline Irritability & $1.68(1.50)$ & 0.31 & -1.32 & * & * \\
\hline Anger & $1.76(1.44)$ & 0.28 & -1.28 & * & * \\
\hline Mania & $2.19(2.22)$ & 0.93 & 0.09 & 0.48 & 0.30 \\
\hline Anxiety & $4.57(3.68)$ & 0.45 & -0.90 & 0.78 & 0.55 \\
\hline Psychosis & $1.35(2.20)$ & 1.70 & 2 & 0.75 & 0.60 \\
\hline Repetitive Thoughts \& Behaviors & $4.63(4.02)$ & 0.97 & 0.44 & 0.68 & 0.35 \\
\hline Substance use & $7.81(0.55)$ & -3.53 & 14.28 & 0.56 & 0.24 \\
\hline Suicidal Ideation/ Attempts & $3.66(0.63)$ & -1.70 & 1.613 & 0.59 & 0.42 \\
\hline
\end{tabular}

Note. ERQ: Emotion Regulation Questionnaire; CCSM: DSM-5 Self-Rated Level 1 Cross-Cutting Symptom Measure-Child Age 11-17; SD: Standard deviation; a: Cronbach's alpha coefficient; MIC: mean interitem correlation; *: internal consistency was not measured because of having one item

carving (34\%), biting (28\%), pulling hair (24\%), banging or hitting $(23 \%)$, severe scratching $(20 \%)$, cutting $(15 \%)$, sticking self with needles (11\%), burning (11\%), rubbing skin against rough surfaces (11\%), pinching (6\%), and swallowing dangerous substances (3\%) (Table 3).

\section{Confirmatory factor analysis}

The results of confirmatory factor analysis showed that the one-factor (RMSEA $=0.101$; CFI $=0.97$, TLI $=0.96)$ and two-factor model of ISAS (RMSEA $=0.098$; CFI $=0.97$, TLI $=0.97$ ) reached adequate fitness according to two fit indices. Nonetheless, we examined modification indices to improve the model fit. Accordingly, for the two-factor model, we added a path from the intrapersonal factor to the self-care function (Table 4). In the original study by Klonsky et al. [4], the self-care function was theoretically expected to load on the intrapersonal factor, but such a result was not found. Consequently, while the RMSEA value decreased, still, it was not in the acceptable recommended $\leq 0.08$ range [39, 40] but was very close to it $($ RMSEA $=0.092 ; \mathrm{CFI}=0.98$, $\mathrm{TLI}=0.97$ ). Nonetheless, some sources consider RMSEA $\leq$ 0.10 as adequate [42]. Thus, our modified two-factor model could also be considered adequate fit based on RMSEA s 0.10 as recommended by Byrne [42], and because other fit indices (i.e., CFI and TLI) were in the excellent range (i.e., $\leq$ $0.95)$ while loadings were above the recommended threshold 
Table 2 Descriptive Statistics of ERQ and CCSM Variables $(n=655)$

\begin{tabular}{|c|c|c|c|c|c|}
\hline Measures & Mean $(S D)$ & Skewness & Kurtosis & $a$ & MIC \\
\hline \multicolumn{6}{|l|}{ ERQ } \\
\hline Cognitive reappraisal & $29.66(6.48)$ & -0.60 & 0.89 & 0.69 & 0.27 \\
\hline Expressive suppression & $16.41(5.51)$ & -0.12 & -0.44 & 0.68 & 0.34 \\
\hline \multicolumn{6}{|l|}{ CCSM } \\
\hline Somatic symptoms & $1.42(1.85)$ & 1.47 & 1.77 & 0.58 & 0.41 \\
\hline Sleep problems & $0.88(1.38)$ & 1.27 & 0.09 & * & * \\
\hline Inattention & $0.85(1.29)$ & 1.33 & 0.47 & * & * \\
\hline Depression & $2.17(2.46)$ & 0.94 & -0.27 & 0.74 & 0.59 \\
\hline Irritability & $1.19(1.42)$ & 0.86 & -0.67 & * & * \\
\hline Anger & $1.18(1.34)$ & 0.86 & -0.51 & * & * \\
\hline Mania & $1.67(2.01)$ & 1.17 & 0.67 & 0.44 & 0.29 \\
\hline Anxiety & $2.96(3.37)$ & 1.08 & 0.09 & 0.80 & 0.58 \\
\hline Psychosis & $0.76(1.74)$ & 2.66 & 6.76 & 0.77 & 0.62 \\
\hline Repetitive Thoughts \& Behaviors & $3.33(3.68)$ & 1.31 & 1.35 & 0.71 & 0.39 \\
\hline Substance use & $7.89(0.40)$ & -4.78 & 26.98 & 0.52 & 0.22 \\
\hline Suicidal Ideation/ Attempts & $3.82(0.45)$ & -2.71 & 6.70 & 0.50 & 0.33 \\
\hline
\end{tabular}

Note. ERQ: Emotion Regulation Questionnaire; CCSM: DSM-5 Self-Rated Level 1 Cross-Cutting Symptom Measure-Child Age 11-17; SD: Standard deviation; a: Cronbach's alpha coefficient; MIC: mean interitem correlation; *: internal consistency was not measured because of having one item

$(<40)$. Since the two-factor model has been supported in previous studies and since this model outperformed the one-factor model though slightly with respect to some fit indices (i.e., RMSEA and TLI), all the analysis from here onwards will be calculated based on the two-factor model.

\section{Internal consistency and correlation between the ISAS scores}

According to Cronbach's alpha and MIC values, the internal consistency of the modified ISAS factors was good
(Table 1). Concerning the ISAS 13 functions, the internal consistency ranged from 0.52 (Interpersonal influence and Sensation seeking) to 0.79 (Autonomy) for interpersonal functions and from 0.62 (Anti-dissociation) to 0.79 (Marking distress) for Intrapersonal functions based on Cronbach's alpha, while all of the functions were in the acceptable range when relying on MIC values. A significant zero-order correlation was found between ISAS factor scores, which was: $r$ Interpersonal-Intrapersonal $=0.79$.

Table 3 Frequency of non-suicidal self-injury $(n=247)$

\begin{tabular}{|c|c|c|c|c|c|c|}
\hline \multirow[t]{2}{*}{ Behavior } & \multicolumn{6}{|c|}{ Frequency } \\
\hline & $n$ & $0-5$ & $5-10$ & $10-15$ & $15-20$ & $<20$ \\
\hline Cutting & 36 & 23 & 5 & 5 & 2 & 1 \\
\hline Bitting & 70 & 42 & 17 & 7 & 2 & 5 \\
\hline Burning & 26 & 18 & 5 & 3 & - & - \\
\hline Carving & 85 & 41 & 18 & 14 & 6 & 6 \\
\hline Pulling Hair & 60 & 38 & 8 & 8 & 1 & 5 \\
\hline Severe Scratching & 49 & 30 & 11 & 4 & 3 & 1 \\
\hline Banging or Hitting Self & 58 & 31 & 12 & 8 & 4 & 3 \\
\hline Interfering w/wound healing (e.g., picking scabs) & 171 & 84 & 27 & 38 & 8 & 14 \\
\hline Sticking Self w/ Needles & 28 & 16 & 4 & 6 & 2 & - \\
\hline Swallowing Dangerous Substances & 8 & 5 & 1 & 2 & - & - \\
\hline Rubbing Skin Against Rough Surface & 27 & 15 & 4 & 5 & 2 & 1 \\
\hline Pinching & 14 & 7 & 3 & 4 & - & - \\
\hline Others & - & - & - & - & - & - \\
\hline
\end{tabular}


Table 4 Factor loadings of ISAS functions $(n=247)$

\begin{tabular}{llc}
\hline Function & Interpersonal Functions & Intrapersonal Functions \\
\hline Affect-regulation & & 0.69 \\
Self-punishment & & 0.64 \\
Anti-dissociation & & 0.82 \\
Marking distress & & 0.82 \\
Self-care & & 0.80 \\
Anti-suicide & 0.71 & 0.66 \\
Interpersonal boundaries & 0.66 & \\
Interpersonal influence & 0.83 & \\
Toughness & 0.81 & \\
Autonomy & 0.72 & \\
Sensation seeking & 0.69 & \\
Revenge & 0.68 & \\
Peer-bonding & & \\
\hline
\end{tabular}

\section{Convergent validity}

Both Interpersonal and Intrapersonal factors were positively related to sleep problems, inattention, depression, irritability, anger, mania, anxiety, psychosis, expressive suppression, and repetitive thoughts and behaviors, but negatively with substance use and suicidal ideation/attempts. Only the Intrapersonal factor had a significant positive relationship with somatic symptoms (Table 5).

\section{Discussion}

The current study examined the psychometric properties and factor structure of ISAS with a sample of Iranian school-attending youth. Our results indicated that the two-factor model initially demonstrated a fair fit. As such, we used the modification indices to improve model fit; thus, the self-care function loaded on the intrapersonal dimension. We concluded that our modified twofactor model has an adequate fit because despite the

Table 5 Correlations between ISAS scores and external correlates

\begin{tabular}{lll}
\hline Measures & ISAS Interpersonal Functions & $\begin{array}{c}\text { ISAS Intrapersonal } \\
\text { Functions }\end{array}$ \\
\hline ISAS Interpersonal Functions & - & - \\
ISAS Intrapersonal Functions & $0.79^{* *}$ & -0.008 \\
ERQ & & $0.22^{* *}$ \\
Cognitive reappraisal & -0.002 & $0.13^{* *}$ \\
Expressive suppression & $0.18^{* *}$ & $0.20^{* *}$ \\
CCSM & & $0.24^{* *}$ \\
Somatic symptoms & 0.05 & $0.33^{* *}$ \\
Sleep problems & $0.16^{* *}$ & $0.37^{* *}$ \\
Inattention & $0.15^{* *}$ & $0.31^{* *}$ \\
Depression & $0.28^{* *}$ & $0.21^{* *}$ \\
Iritability & $0.33^{* *}$ & $0.41^{* *}$ \\
Anger & $0.31^{* *}$ & $0.30^{* *}$ \\
Mania & $0.29^{* *}$ & $0.28^{* *}$ \\
Anxiety & $0.40^{* *}$ & $-0.18^{* *}$ \\
Psychosis & $0.37^{* *}$ & $-0.44^{* *}$ \\
Repetitive Thoughts \& Behaviors & $0.25^{* *}$ & $-0.25^{* *}$ \\
Substance use & $-0.44^{* *}$ & \\
Suicidal Ideation/ Attempts & \\
\hline NoteERQ: Emion Regution & \\
\end{tabular}

Note. ERQ: Emotion Regulation Questionnaire; CCSM: DSM-5 Self-Rated Level 1 Cross-Cutting Symptom Measure-Child Age 11-17; **p<.001 
RMSEA not reaching the recommended range $\leq 0.08$, other fit indices were in the excellent range, and factor loadings were significantly higher than the threshold of 0.40 . Our results concerning the RMSEA are consistent with previous research. For example, in a study in South Korea [3], the RMSEA was 0.10, while CFI was 0.91 . Similarly, in the Turkish study [24], the results yielded an RMSEA of 0.08 and CFI of 0.97. Also, in line with previous studies [25, 28], our results indicated that selfcare function aligned as an intrapersonal function. This was theoretically expected but not found in the original study by Klonsky et al. [4].

Echoing previous studies $[3,4,24,25,28,31]$, our results indicated that the internal consistency of the ISAS dimensions was good. In addition, all of the functions had acceptable MIC values and were internally consistent. These results are very consistent with the findings of Klonsky et al. [4].

The current study also examined associations between ISAS scores and external criterion measures to bolster what is known about the convergent validity of the Persian version of ISAS. Consistent with previous studies $[4,24,26,43-48]$, both ISAS dimensions were positively related to sleep problems, inattention, depression, irritability, anger, mania, anxiety, psychosis, and repetitive thoughts and behaviors; also, only Intrapersonal factor had a significant positive relationship with somatic symptoms. Our results also indicated that ISAS scores had significant positive correlations with expressive suppression, while they were not correlated with cognitive reappraisal. This finding is consistent with Gross and John [36] in that reappraisers experience and express greater positive and lesser negative emotions, whereas suppressors experience and express lesser positive emotions, yet experience greater negative ones. To our surprise, both Intrapersonal and Interpersonal dimensions were negatively associated with substance use and suicidal ideation/attempt. This might be due to the fact that our sample included 13-17 years old school attending adolescents who usually do not have access to illegal substances. Also, in Iran, suicidal behavior is strongly prohibited by religious and socio-cultural factors. For instance, in Iran's schools, based on Islamic instruction, adolescents learn that suicide attempt is amongst gravest sins in Islam, and such an attempt, would deprive the individual of the paradise and its merits. Thus, individuals may feel guilty when they think about attempting suicide, and they may engage in NSSI instead of suicidal attempts. Notwithstanding, this aspect of the measure's convergent validity remains unclear, and further studies are needed to explore this finding. In sum, our results support the convergent validity of the interpretation of the ISAS dimension in Iranian school-attending adolescents.

\section{Limitations}

Our findings should be interpreted in the context of several limitations. First, we used only self-report measures. Therefore, correlations between ISAS scores and external correlates may partly be explained by shared method variance. Second, since the current study had a crosssectional nature, conclusions about causality between ISAS scores and correlated variables should not be drawn. Finally, the study sample included only school attending adolescents, so future studies are recommended to study the psychometric of the ISAS with clinical samples.

\section{Conclusions}

Overall, the Persian version of the ISAS can be widely used as a valid and reliable self-report measure of NSSI in research studies and clinical settings with adolescents in Iran as it yielded excellent internal consistency and associations with the external correlates of interest.

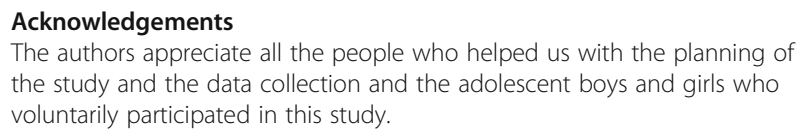

\section{Funding}

This study was financially supported by the University of Social Welfare \& Rehabilitation Sciences (grant number: 2556).

\section{Availability of data and materials}

The datasets generated during and/or analyzed during the current study are available from the corresponding author on reasonable request.

\section{Declarations}

Ethics approval and consent to participate

The ethics committee of the Psychosis Research Center, University of Social Welfare and Rehabilitation Sciences approved this study (code number: IR.USWR.REC.1399.223). All participants provided online informed consent after reading the study purpose and being assured about the confidentiality of data.

\section{Consent for publication}

Not applicable.

\section{Competing interests}

There was no conflict of interest in this study.

\section{Author details}

${ }^{1}$ Psychosis Research Center, the University of Social Welfare and Rehabilitation Sciences, Tehran, Iran. ${ }^{2}$ School of Behavioral Sciences and Mental Health (Tehran Institute of Psychiatry), Iran University of Medical Sciences, Tehran, Iran. ${ }^{3}$ Candidate in Clinical Psychology, the University of Social Welfare and Rehabilitation Sciences, 1985713871 Tehran, Iran. ${ }^{4}$ Segal Counseling \& Psychological Services Center, Tehran, Iran. ${ }^{5}$ University of Social Welfare and Rehabilitation Sciences, Tehran, Iran. ${ }^{6}$ Department of Psychiatry and Behavioral Sciences, Baylor College of Medicine, TX, Houston, USA. 
Received: 31 August 2021 Accepted: 20 October 2021

Published online: 12 November 2021

\section{References}

1. American Psychiatric Association. Diagnostic and statistical manual of mental disorders (DSM-5 ${ }^{\oplus}$ ). American Psychiatric Pub; 2013.

2. Nock MK, Favazza AR. Nonsuicidal self-injury: Definition and classification. Understanding nonsuicidal self-injury: Origins, assessment, and treatment. Washington, DC, US: American Psychological Association; 2009. p. 9-18. https://doi.org/10.1037/11875-001.

3. Kim S, Kim Y-A, Hur J-W. Nonsuicidal Self-Injury among Korean Young Adults: A Validation of the Korean Version of the Inventory of Statements about Self-Injury. Psychiatry Investigation. 2019;16:270-8. https://doi.org/10.3 0773/pi.2019.01.23

4. Klonsky ED, Glenn CR. Assessing the functions of non-suicidal self-injury: Psychometric properties of the Inventory of Statements About Self-injury (ISAS). Journal of psychopathology behavioral assessment. 2009;31(3):215-9. doi:https://doi.org/10.1007/s10862-008-9107-z.

5. Klonsky ED, Oltmanns TF, Eric T. Deliberate Self-Harm in a Nonclinical Population: Prevalence and Psychological Correlates. Am J Psychiatry. 2003; 160(8):1501-8. doi:https://doi.org/10.1176/appi.ajp.160.8.1501.

6. Robinson K, Brocklesby M, Garisch JA, O'Connell A, Langlands R, Russell L, et al. Socioeconomic deprivation and non-suicidal self-injury in New Zealand adolescents: The mediating role of depression and anxiety. New Zealand Journal of Psychology. 2017;46(3):126-36.

7. Muehlenkamp JJ, Xhunga N, Brausch AM. Self-injury Age of Onset: A Risk Factor for NSSI Severity and Suicidal Behavior. Archives of Suicide Research. 2019;23(4):551-63. doi:https://doi.org/10.1080/13811118.2018.1486252.

8. Toprak S, Cetin I, Guven T, Can G, Demircan C. Self-harm, suicidal ideation and suicide attempts among college students. Psychiatry research. 2011; 187(1-2):140-4. doi:https://doi.org/10.1016/j.psychres.2010.09.009.

9. Nisar H, Aqeel M, Ahmad A. Indigenous need arise to protect human from self-harm behavior in Pakistan: translation and validation of inventory of statements about self-injury. International Journal of Human Rights in Healthcare. 2020. doi:https://doi.org/10.1108/IJHRH-10-2019-0080.

10. Claes L, Norré J, Van Assche L, Bijttebier P. Non-suicidal self-injury (functions) in eating disorders: Associations with reactive and regulative temperament. Personality Individ Differ. 2014;57:65-9. doi:https://doi.org/10.1016/j.paid.2 013.09.022.

11. Nock MK, Prinstein MJ. A functional approach to the assessment of selfmutilative behavior. J Consult Clin Psychol. 2004;72(5):885. doi:https://doi. org/10.1037/0022-006X.72.5.885

12. Groschwitz RC, Plener PL, Kaess M, Schumacher T, Stoehr R, Boege I. The situation of former adolescent self-injurers as young adults: a follow-up study. BMC Psychiatry. 2015;15(1):1-9. doi:https://doi.org/10.1186/s12888-01 5-0555-1.

13. de Neira MD, García-Nieto R, de León-Martinez V, Fominaya MP, Baca-García E, Carballo JJ. Prevalencia y funciones de los pensamientos y conductas autoagresivas en una muestra de adolescentes evaluados en consultas externas de salud mental. Revista de psiquiatría y salud mental. 2015;8(3): 137-45. doi:https://doi.org/10.1016/j.rpsm.2013.09.003.

14. Gholamrezaei M, Heath N, Panaghi L. Non-suicidal self-injury in a sample of university students in Tehran, Iran: prevalence, characteristics and risk factors. International Journal of Culture Mental Health. 2017;10(2):136-49. doi:https://doi.org/10.1080/17542863.2016.1265999.

15. Kaess M, Parzer P, Mattern M, Plener PL, Bifulco A, Resch F, et al. Adverse childhood experiences and their impact on frequency, severity, and the individual function of nonsuicidal self-injury in youth. Psychiatry research. 2013;206(2-3):265-72. doi:https://doi.org/10.1016/j.psychres.2012.10.012.

16. Thomassin K, Shaffer A, Madden A, Londino DL. Specificity of childhood maltreatment and emotion deficit in nonsuicidal self-injury in an inpatient sample of youth. Psychiatry research. 2016;244:103-8. doi:https://doi.org/1 0.1016/j.psychres.2016.07.050

17. Weismoore JT, Esposito-Smythers $C$. The role of cognitive distortion in the relationship between abuse, assault, and non-suicidal self-injury. J Youth Adolesc. 2010;39(3):281-90. doi:https://doi.org/10.1007/s10964-009-9452-6.

18. Zetterqvist $M$, Lundh L-G, Svedin CG. A cross-sectional study of adolescent non-suicidal self-injury: support for a specific distress-function relationship. Child Adolesc Psychiatry Mental Health. 2014:8(1):1-14. doi:https://doi.org/1 $0.1186 / 1753-2000-8-23$
19. Plener PL, Schumacher TS, Munz LM, Groschwitz RC. The longitudinal course of non-suicidal self-injury and deliberate self-harm: a systematic review of the literature. Borderline Personality Disorder Emotion Dysregulation. 2015;2(1):2. doi:https://doi.org/10.1186/s40479-014-0024-3.

20. Brown RC, Plener PL. Non-suicidal Self-Injury in Adolescence. Curr Psychiatry Rep. 2017:19(3):20. doi:https://doi.org/10.1007/s11920-017-0767-9.

21. Baiden P, Stewart SL, Fallon B. The role of adverse childhood experiences as determinants of non-suicidal self-injury among children and adolescents referred to community and inpatient mental health settings. Child Abuse Negl. 2017;69:163-76. doi:https://doi.org/10.1016/j.chiabu.2017.04.011.

22. Swannell SV, Martin GE, Page A, Hasking P, St John NJ. Prevalence of nonsuicidal self-injury in nonclinical samples: Systematic review, metaanalysis and meta-regression. Suicide Life-Threatening Behavior. 2014;44(3): 273-303.

23. Lindholm T, Bjärehed J, Lundh L-G. Functions of nonsuicidal self-injury among young women in residential care: a pilot study with the Swedish version of the inventory of statements about self-injury. Cogn Behav Ther. 2011;40(3):183-9. doi:https://doi.org/10.1080/16506073.2011.565791.

24. Bildik T, Somer O, BASAY BK, BASAY Ö, Özbaran B. The validity and reliability of the Turkish version of the inventory of statements about self-injury. Turk Psikiyatri Dergisi. 2013;24(1):49. doi:https://doi.org/10.5080/u6901.

25. Kortge R, Meade T, Tennant A. Interpersonal and intrapersonal functions of deliberate self-harm (DSH): A psychometric examination of the Inventory of Statements About Self-Injury (ISAS) scale. Behaviour Change. 2013;30(1):2435. doi:https://doi.org/10.1017/bec.2013.3.

26. Pérez S, García-Alandete J, Cañabate M, Marco JH. Confirmatory factor analysis of the Inventory of Statements About Self-injury in a Spanish clinical sample. Journal of clinical psychology. 2020;76(1):102-17. doi:https:// doi.org/10.1002/jclp.22844.

27. Zarghami M, Babakhanian M, Habibi Asgarabad M, Ghazanfanpour M, Akrami FS, Nazeri N, et al. Psychometric Properties of the Inventory of Statements About Self-Injury (ISAS) in Iranian Opioid and Alcohol Abusers. Iran J Psychiatry Behav Sci. 2020;14(4):e88494. doi:https://doi.org/10.5812/ ijpbs.88494.

28. Vigfusdottir J, Dale KY, Gratz KL, Klonsky ED, Jonsbu E, Høidal R. The psychometric properties and clinical utility of the Norwegian versions of the deliberate self-harm inventory and the inventory of statements about selfinjury. Current Psychology. 2020. doi:https://doi.org/10.1007/s12144-020-011 89-y.

29. Cortina JM. Big Things Have Small Beginnings: An Assortment of "Minor" Methodological Misunderstandings. J Manag. 2002;28(3):339-62. doi:https:// doi.org/10.1177/014920630202800305.

30. Landis R, Edwards B, Cortina J. (2009). Correlated residuals among items in the estimation of measurement models. Statistical and methodological myths and urban legends: Doctrine, verity, and fable in the organizational and social sciences, 195-214

31. Silva EC, Benjet C, García FJ, Cárdenas SJ, Gómez-Maqueo MEL, Cruz AV. Adaptation and psychometric properties of the Inventory of Statements About Self-injury in Mexican students. Acta de Investigación Psicológica. 2016. doi:https://doi.org/10.1016/j.aipprr.2016.08.004.

32. Taheri $\mathrm{E}$, Athar ME, Ebrahimi A, Atashipoor HS, Taheri M, Mollaee H. The Persian Version of the Personality Beliefs Questionnaire-Short-Form (PBQ-SF): A Psychometric Evaluation. J Rational-Emot Cognitive-Behav Ther. 2021. doi: https://doi.org/10.1007/s10942-021-00420-4.

33. Elhami Athar M, Ebrahimi A. Psychometric Properties and Factor Structure of the Personality Inventory for DSM-5-Brief Form (PID-5-BF) in Iranian Student and Clinical Samples. BMC Psychiatry. 2021. doi:https://doi.org/10.21203/rs.3. rs-440296/v1.

34. Ebrahimi A, Elhami Athar M, Hakim Shooshtari M, Karsazi H, Storch EA. (2021). Psychometric Properties of the Persian Version of the Teasing Questionnaire 23. Front Psychol, 12. doi:https://doi.org/10.3389/fpsyg.2021.664736.

35. Nobakht HN, Dale KY. The prevalence of deliberate self-harm and its relationships to trauma and dissociation among Iranian young adults. Journal of Trauma Dissociation. 2017;18(4):610-23. doi:https://doi.org/10.1 080/15299732.2016.1246397.

36. Gross JJ, John OP. Individual differences in two emotion regulation processes: implications for affect, relationships, and well-being. J Pers Soc Psychol. 2003; 85(2):348-62. doi:https://doi.org/10.1037/0022-3514.85.2.348.

37. Hasani J. Persian Version of the Emotion Regulation Questionnaire: Factor Structure, Reliability and Validity. International Journal of Behavioral Sciences. 2016;10(3):108-13. 
38. Du Toit M, Du Toit SHC, Hawkins DM. Interactive LISREL: User's guide. Scientific Software International; 2001.

39. Bentler PM. Comparative fit indexes in structural models. Psychol Bull. 1990; 107(2):238-46. doi:https://doi.org/10.1037/0033-2909.107.2.238.

40. Lt Hu, Bentler PM. Cutoff criteria for fit indexes in covariance structure analysis: Conventional criteria versus new alternatives. Structural Equation Modeling: A Multidisciplinary Journal. 1999;6(1):1-55. doi:https://doi.org/10.1 080/10705519909540118.

41. Clark LA, Watson D. Constructing Validity: Basic Issues in Objective Scale Development. Psychol Assess. 1995;7(3):309-19.

42. Byrne BM. Structural equation modeling with EQS: Basic concepts, applications, and programming. Routledge; 2013

43. Khazaie H, Zakiei A, McCall WW, Noori K, Rostampour M, Sadeghi Bahmani D, et al. (2020). Relationship between Sleep Problems and Self-Injury: A Systematic Review. Behav Sleep Med, 1-16. doi:https://doi.org/10.1080/154 02002.2020.1822360.

44. Andover MS, Morris BW. Suicidal and nonsuicidal self-injury in the obsessive-compulsive spectrum. In: Obsessive-compulsive disorder and its spectrum: A life-span approach. Washington, DC, US: American Psychological Association; 2014. pp. 241-59.

45. Koyanagi A, Stickley A, Haro JM. Psychotic-Like Experiences and Nonsuicidal Self-Injury in England: Results from a National Survey [corrected]. PloS one. 2015;10(12):e0145533. doi:https://doi.org/10.1371/journal.pone.0145533.

46. Esposito-Smythers C, Goldstein T, Birmaher B, Goldstein B, Hunt J, Ryan N, et al. Clinical and psychosocial correlates of non-suicidal self-injury within a sample of children and adolescents with bipolar disorder. J Affect Disord. 2010;125(1):89-97. doi:https://doi.org/10.1016/j.jad.2009.12.029.

47. Hasking PA, Coric SJ, Swannell S, Martin G, Thompson HK, Frost ADJ. Brief report: Emotion regulation and coping as moderators in the relationship between personality and self-injury. J Adolesc. 2010;33(5):767-73. doi: https://doi.org/10.1016/j.adolescence.2009.12.006.

48. Croyle KL, Waltz J. Subclinical Self-Harm: Range of Behaviors, Extent, and Associated Characteristics. Am J Orthopsychiatry. 2007;77(2):332-42. doi: https://doi.org/10.1037/0002-9432.77.2.332.

\section{Publisher's Note}

Springer Nature remains neutral with regard to jurisdictional claims in published maps and institutional affiliations.

Ready to submit your research? Choose BMC and benefit from:

- fast, convenient online submission

- thorough peer review by experienced researchers in your field

- rapid publication on acceptance

- support for research data, including large and complex data types

- gold Open Access which fosters wider collaboration and increased citations

- maximum visibility for your research: over $100 \mathrm{M}$ website views per year

At $\mathrm{BMC}$, research is always in progress.

Learn more biomedcentral.com/submissions 